\title{
Drugs in secondary stroke prevention
}

\section{SUMMARY}

After an ischaemic stroke or transient ischaemic attack, patients have a high risk of having another stroke. Secondary stroke prevention includes antiplatelet therapy, statins and antihypertensives.

Aspirin, clopidogrel, or a combination of aspirin with dipyridamole are first-line options for secondary stroke prevention in the absence of atrial fibrillation.

Dual antiplatelet therapy has a benefit in the first three weeks after stroke, but patients should change to a single antiplatelet drug after this time.

Anticoagulants are indicated if the patient has atrial fibrillation. Avoid combinations of anticoagulants and antiplatelet drugs.

Patients should be started on statins after an ischaemic stroke. High doses are recommended even if cholesterol concentrations are normal.

Antihypertensive drugs are recommended for all patients with systolic blood pressures greater than 140/90 mmHg. ACE inhibitors, calcium channel blockers and diuretics are first-line options.

\section{Introduction}

Each year almost 20,000 Australians have a stroke, the majority of which are ischaemic. The 10-year recurrence rate following a first stroke is over $40 \%{ }^{2}$ To prevent recurrences patients are managed with a combination of drugs and lifestyle modification. Pharmacotherapy is critical for optimising outcomes for patients after an ischaemic stroke or transient ischaemic attack (see Fig.). Treatment recommendations change regularly, and as such there are a set of living guidelines for secondary stroke prevention that are continually reviewed and updated. ${ }^{3}$ Adherence to treatment is also important.

\section{Antiplatelet drugs}

The efficacy of antiplatelet drugs for secondary stroke prevention is well established. ${ }^{4}$ Antiplatelet therapy should start as soon as possible following a stroke or transient ischaemic attack. ${ }^{5}$ Current Australian guidelines recommend either aspirin, clopidogrel or a combination of aspirin and dipyridamole (see Table). Antiplatelets carry some risk of gastrointestinal bleeding. The routine use of proton pump inhibitors is restricted to those considered higher risk, for example patients with a history of gastrointestinal ulcer, or those over 60 years with gastro-oesophageal reflux disease. ${ }^{6}$

\section{Aspirin}

A 2016 meta-analysis found that aspirin at daily doses of 75-162 mg or 500-1500 mg reduced long-term recurrence of stroke more than placebo. ${ }^{7}$ However, there was an increased risk of bleeding with the increased dose range, so typically doses of 75-150 mg are used. The benefit of aspirin has been shown to be even more marked for secondary stroke prevention in the first six weeks post stroke. ${ }^{5}$

\section{Aspirin/dipyridamole}

Dipyridamole should not be used alone in stroke prevention. In trials it was combined with aspirin, typically as aspirin $25 \mathrm{mg}$ and dipyridamole $200 \mathrm{mg}$. This is an acceptable antiplatelet combination for patients with non-cardioembolic ischaemic stroke or transient ischaemic attack.

The 2006 ESPRIT trial found that the combination of aspirin and dipyridamole had a benefit over aspirin alone with regard to secondary stroke risk, and nonfatal bleeding. ${ }^{8}$ It is worth noting however that the majority of patients were randomised after more than one month, and so it is unclear if aspirin/dipyridamole has benefit over aspirin immediately after a stroke.

Dipyridamole has a vasodilatory action and headache is a common adverse effect which may lower adherence to treatment. ${ }^{9}$ Dipyridamole's vasodilatory effect also means care should be used in patients with unstable angina or aortic stenosis.

\section{$P 2 Y_{12}$ inhibitors}

Clopidogrel, a P2Y $Y_{12}$ inhibitor, has efficacy for secondary stroke prevention at doses of $75 \mathrm{mg} .{ }^{10} \mathrm{~A}$ 2019 meta-analysis found a benefit for clopidogrel over aspirin and aspirin/dipyridamole for reducing major bleeding and intracranial haemorrhage."
Chris Tremonti (D)

Advanced trainee in Clinical Pharmacology'

\section{Mark Thieben}

Neurologist ${ }^{2}$

'Royal Prince Alfred

Hospital

2 Royal North Shore Hospital

Sydney

\section{Keywords}

anticoagulants, antiplatelet drugs, cerebrovascular disease, stroke

Aust Prescr 2021:44:85-90 https://doi.org/10.18773/ austprescr.2021.018 


\section{Fig. Drugs for secondary stroke prevention}

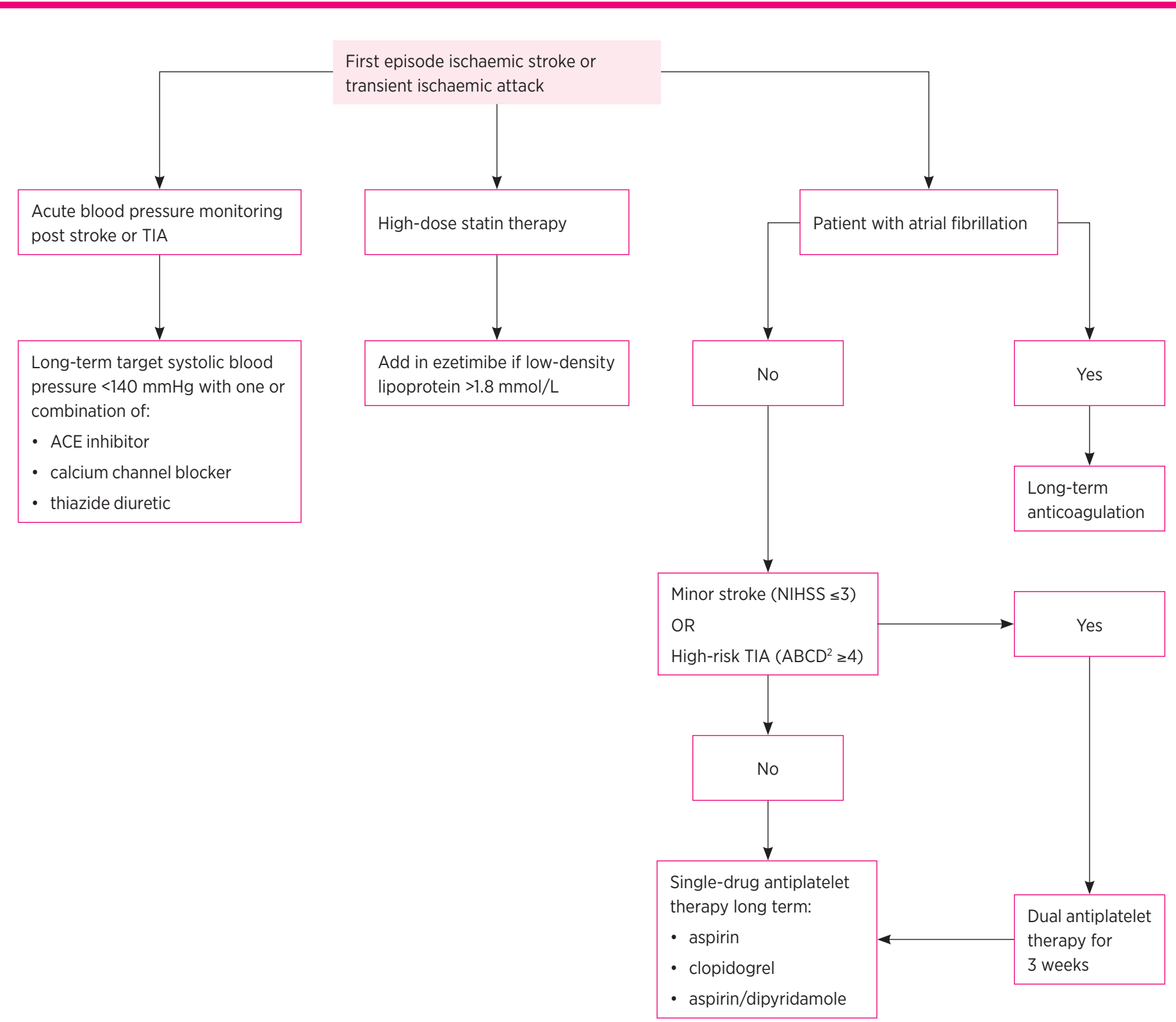

NIHSS National Institutes of Health Stroke Scale

\section{Table Comparative efficacy of antiplatelet drugs for secondary stroke prevention}

\begin{tabular}{|c|c|c|c|}
\hline & Aspirin versus placebo & Clopidogrel versus placebo & Aspirin/dipyridamole versus placebo \\
\hline $\begin{array}{l}\text { Recurrent stroke } \\
\text { (up to } 27 \text { months) }\end{array}$ & $\begin{array}{l}\text { Odds ratio } 0.78 \\
(95 \% \mathrm{Cl} 0.63-0.99)\end{array}$ & $\begin{array}{l}\text { Odds ratio } 0.68 \\
(95 \% \mathrm{Cl} 0.53-0.92)\end{array}$ & $\begin{array}{l}\text { Odds ratio } 0.69 \\
(95 \% \mathrm{Cl} 0.56-0.89)\end{array}$ \\
\hline $\begin{array}{l}\text { Bleeding } \\
\text { (up to } 27 \text { months) }\end{array}$ & $\begin{array}{l}\text { Odds ratio } 2.33 \\
(95 \% \mathrm{Cl} 1.73-3.30)\end{array}$ & $\begin{array}{l}\text { Odds ratio } 1.79 \\
(95 \% \mathrm{Cl} 1.23-2.78)\end{array}$ & $\begin{array}{l}\text { Odds ratio } 1.95 \\
(95 \% \mathrm{Cl} 1.43-2.78)\end{array}$ \\
\hline $\begin{array}{l}\text { Serious vascular event } \\
\text { (up to } 27 \text { months) }\end{array}$ & $\begin{array}{l}\text { Odds ratio } 0.83 \\
\text { (95\% Cl 0.71-0.96) }\end{array}$ & $\begin{array}{l}\text { Odds ratio } 0.74 \\
(95 \% \mathrm{Cl} 0.65-0.86)\end{array}$ & $\begin{array}{l}\text { Odds ratio } 0.72 \\
(95 \% \mathrm{Cl} 0.63-0.83 \text { ) }\end{array}$ \\
\hline
\end{tabular}

Adapted from reference 3

$\mathrm{Cl}$ confidence interval 
Ticagrelor, another $\mathrm{P}_{2} \mathrm{Y}_{12}$ antagonist, has not been shown to offer a benefit over aspirin for monotherapy.12 It is not recommended in guidelines or approved by the Therapeutic Goods Administration for stroke prevention in Australia.

\section{Recurrent stroke while on antiplatelet therapy}

Patients may have 'breakthrough' cryptogenic strokes despite antiplatelet therapy. It is worth discussing the patient's adherence to treatment and working with them on strategies to improve this if there is a problem. ${ }^{13}$

Studies have shown that patients adherent with aspirin benefit from a change to a different antiplatelet drug if they have a breakthrough ischaemic stroke. ${ }^{14,15}$ 'Clopidogrel resistance' is a phenomenon well studied in acute coronary syndrome, but less so in stroke, making it a challenge to guide management of breakthrough stroke on clopidogrel. ${ }^{16}$ Screening for clopidogrel resistance is not currently recommended. ${ }^{17}$

\section{Dual antiplatelet therapy}

Dual antiplatelet therapy in secondary stroke prevention has received increased attention due to two major randomised controlled trials - CHANCE and POINT. CHANCE found aspirin and clopidogrel given together for the first 21 days after a high-risk transient ischaemic attack $\left(A B C D^{2} \geq 4\right)^{18}$ or minor stroke (National Institutes of Health Stroke Scale $\leq 3)^{19}$ reduced recurrence without a risk of increased bleeding compared to aspirin alone. ${ }^{20}$ The POINT study showed a reduction in ischaemic stroke at 90 days for patients on the aspirin/clopidogrel combination compared to aspirin alone in minor stroke or high-risk transient ischaemic attack, at the cost of an increased rate of major haemorrhage. ${ }^{21} \mathrm{~A}$ subsequent meta-analysis including both trials has suggested that dual antiplatelets appear to be most beneficial in the first three weeks following minor stroke. ${ }^{22}$ In Australia, the Stroke Foundation currently advises using dual antiplatelet therapy for three weeks after a non-valvular, non-arrhythmic, minor ischaemic stroke or high-risk transient ischaemic attack then switching to monotherapy. ${ }^{3}$ There is no evidence to continue dual therapy beyond 90 days. For larger strokes (NIHSS $>3$ ), the risk of bleeding from dual antiplatelet therapy outweighs the benefits and is not routine practice.

The combination of aspirin with ticagrelor was recently compared to aspirin alone in the first 30 days after a stroke. This THALES study found the combination to be superior for prevention of stroke or death, but with an increased risk of major bleeding. ${ }^{23}$ Ticagrelor is not currently listed on the Pharmaceutical
Benefits Scheme for stroke prevention, and like other combinations, the combination with aspirin has no evidence beyond 30 days.

Dual antiplatelet therapy will typically be used for 30 days after carotid artery stenting. However, there is no evidence to support dual antiplatelet therapy after carotid endarterectomy. ${ }^{24}$

\section{Anticoagulants and atrial fibrillation}

The evidence for anticoagulants for the secondary prevention of ischaemic stroke in a patient with non-rheumatic atrial fibrillation without mechanical heart valves is unequivocal. ${ }^{25,26}$ The direct oral anticoagulants are now preferred to warfarin for secondary stroke prevention. This is because a metaanalysis found non-inferiority for preventing ischaemic stroke and superiority for rates of haemorrhagic stroke. ${ }^{27}$ Warfarin does have some advantages in the risk of gastrointestinal bleeding, and can also be used in patients with an estimated glomerular filtration rate (eGFR) below $15 \mathrm{~mL} /$ minute. The choice of direct oral anticoagulant is individualised based on renal function, ability to adhere to the dosing schedule and the likely need for reversal of anticoagulation. ${ }^{28}$

There are concerns that cryptogenic strokes may be due to undiagnosed paroxysmal atrial fibrillation, ${ }^{29,30}$ creating the idea that anticoagulants may have a role even if the arrhythmia is not detected. ${ }^{31,32}$ However, evidence to support this is lacking, and anticoagulants post stroke without evidence of atrial fibrillation are not recommended for secondary stroke prevention due to the increased risk of bleeding. ${ }^{33}$

There is no role for antiplatelets in secondary stroke prevention in patients with atrial fibrillation as they should be anticoagulated. After a stroke, patients taking anticoagulants for atrial fibrillation should stop antiplatelet drugs, unless there is another indication for antiplatelet therapy, such as previous acute myocardial infarction or coronary stents. Clinicians should liaise with the patient's cardiologist with a view to stopping the antiplatelet drugs when possible.

\section{Blood pressure management}

The Australian Clinical Guidelines for Stroke Management currently recommend a reduction of systolic blood pressure to less than $140 \mathrm{mmHg} .{ }^{3} \mathrm{~A}$ target of below $130 \mathrm{mmHg}$ has been suggested to offer a small additional benefit in secondary stroke prevention for patients with lacunar infarcts. This comes at the risk of increased unsteadiness, especially in older patients. ${ }^{34,35}$ The blood pressure target will also depend on evidence of other sequelae of hypertension, such as renal impairment.

ACE inhibitors, calcium channel blockers and thiazide diuretics are first-line options for blood pressure control 


\section{SELF-TEST QUESTIONS}

True or false?

1. After a stroke, all patients should take an anticoagulant for secondary stroke prevention.

2. After a stroke, normotensive patients should be started on antihypertensive drugs.

Answers on page 113 after a stroke. ${ }^{36}$ The choice should be individualised for each patient. A large meta-analysis of cardiovascular outcomes found beta blockers may be inferior to other antihypertensive drugs in stroke prevention. ${ }^{37}$

Adherence to diuretics has been shown repeatedly to be worse than with other antihypertensives. ${ }^{38}$ The adherence to the other drugs is around $80 \%$ one year after the stroke. Programs designed to increase patient adherence and improve blood pressure long term have shown some benefit on adherence, but not on blood pressure. ${ }^{39}$ Of concern, however, is evidence that people who remain hypertensive after a stroke are under-prescribed antihypertensive drugs despite a clear benefit in stroke prevention. ${ }^{40}$

\section{Cholesterol management}

High-dose statins, such as atorvastatin $80 \mathrm{mg}$ or rosuvastatin $40 \mathrm{mg}$, are first-line treatment for all patients following ischaemic strokes regardless of their cholesterol. ${ }^{3}$ This is because a meta-analysis found high-dose statins offered a protective effect against further ischaemic strokes even when cholesterol was not elevated. ${ }^{41}$ There had been concerns that statins may cause an increase in intracerebral haemorrhage based on results from the SPARCL trial and the Heart Protection Study. ${ }^{42,43}$ However, this was not borne out in a subsequent meta-analysis, which also reported that statins improved all-cause mortality, functional outcome, and the risk of stroke regardless of type. ${ }^{44}$ In patients who cannot tolerate high-dose statins, low-dose statins should still be tried.

\section{A 2020 randomised controlled trial found that a} target low-density lipoprotein concentration of less than $1.8 \mathrm{mmol} / \mathrm{L}$ had benefit in protecting patients post stroke from cardiovascular events, compared to a target of 2.3-2.8 mmol/L. ${ }^{45}$ Patients in the lower target group typically received ezetimibe if their cholesterol remained elevated, although there was no fixed regimen. Ezetimibe is also recommended for patients who are statin intolerant as second-line therapy. ${ }^{46}$ This is mainly based on the IMPROVE-IT trial, which studied patients with acute coronary syndrome. ${ }^{47}$ It is unclear if ezetimibe works as monotherapy. ${ }^{48}$ The main adverse effects of ezetimibe include myalgias, headaches and hepatitis.

Fibrates have not been shown to be beneficial in secondary stroke prevention. They are not recommended in treatment guidelines. ${ }^{49,50}$

\section{Conclusion}

After a stroke, patients are at risk of further ischaemic strokes, particularly in the first few weeks. Antiplatelet drugs, statins and antihypertensive drugs are the mainstay of pharmacotherapy for secondary stroke prevention. If dual antiplatelet therapy is used after a stroke, clinicians should ensure patients return to single drug therapy three weeks later. Patients with atrial fibrillation should be anticoagulated. Combinations of anticoagulants and antiplatelets should be avoided if possible. Liaise with the patient's neurologist and cardiologist if the patient is taking anticoagulants and antiplatelets to confirm whether combined treatment is intended.

The target blood pressure should be less than $140 \mathrm{mmHg}$ systolic. ACE inhibitors, calcium channel blockers or thiazide diuretics can be used. Statins are first-line treatment and a target low-density lipoprotein of less than $1.8 \mathrm{mmol} / \mathrm{L}$ is now recommended. $<$

Conflicts of interest: none declared

\section{REFERENCES}

1. Breen S, Cadilhac DA, Lannin NA, Kim J, Dalli L, Anderson CS et al. on behalf of the AuSCR Consortium. The Australian Stroke Clinical Registry Annual Report 2019 Volume 1: Acute care provision. Melbourne: The Florey Institute of Neuroscience and Mental Health; 2020. Report No. 11. https://auscr.com.au/ about/annual-reports/ [cited 2021 May 1]

2. Hardie K, Hankey GJ, Jamrozik K, Broadhurst RJ, Anderson C. Ten-year risk of first recurrent stroke and disability after first-ever stroke in the Perth Community Stroke Study. Stroke 2004;35:731-5. https://doi.org/10.1161/ 01.str.0000116183.50167.d9

3. Stroke Foundation. Australian Clinical Guidelines for Stroke Management - Chapter 4 of 8: Secondary prevention. Updated 2021 Mar 22. https://app.magicapp.org/\#/ guideline/5017 [cited 2021 May 1]

4. Baigent C, Sudlow C, Collins R, Peto R; Antithrombotic Trialists' Collaboration. Collaborative meta-analysis of randomised trials of antiplatelet therapy for prevention of death, myocardial infarction, and stroke in high risk patients. BMJ 2002;324:71-86. https://doi.org/10.1136/bmj.324.7329.71

5. Rothwell PM, Algra A, Chen Z, Diener HC, Norrving B, Mehta Z. Effects of aspirin on risk and severity of early recurrent stroke after transient ischaemic attack and ischaemic stroke: timecourse analysis of randomised trials. Lancet 2016;388:365-75. https://doi.org/10.1016/S0140-6736(16)30468-8

6. Bhatt DL, Scheiman J, Abraham NS, Antman EM, Chan FK Furberg CD, et al.; American College of Cardiology Foundation Task Force on Clinical Expert Consensus Documents. ACCF/ACG/AHA 2008 expert consensus document on reducing the gastrointestinal risks of antiplatelet therapy and NSAID use: a report of the American College of Cardiology Foundation Task Force on Clinical Expert Consensus Documents. Circulation 2008;118:1894-909. https://doi.org/10.1161/ CIRCULATIONAHA.108.191087

7. Niu PP, Guo ZN, Jin H, Xing YQ, Yang Y. Antiplatelet regimens in the long-term secondary prevention of transient ischaemic attack and ischaemic stroke: an updated network meta-analysis. BMJ Open 2016;6:e009013. https://doi.org/ 10.1136/bmjopen-2015-009013

8. ESPRIT Study Group. Aspirin plus dipyridamole versus aspirin alone after cerebral ischaemia of arterial origin (ESPRIT): randomised controlled trial. Lancet 2006;367:1665-73. https://doi.org/10.1016/S0140-6736(06)68734-5

9. Hackam DG, Spence JD. Antiplatelet therapy in ischaemic stroke and transient ischemic attack: an overview of major trials and meta-analyses. Stroke 2019;50:773-8. https://doi.org/10.1161/STROKEAHA.118.023954 
10. CAPRIE Steering Committee. A randomised, blinded, trial of clopidogrel versus aspirin in patients at risk of ischaemic events (CAPRIE). Lancet 1996;348:1329-39. https://doi.org/ 10.1016/S0140-6736(96)09457-3

11. Greving JP, Diener HC, Reitsma JB, Bath PM, Csiba L, Hacke W, et al. Antiplatelet therapy after noncardioembolic stroke: an individual patient data network metaanalysis. Stroke 2019;50:1812-8. https://doi.org/10.1161/ STROKEAHA.118.024497

12. Johnston SC, Amarenco P, Albers GW, Denison H, Easton JD, Evans SR, et al.; SOCRATES Steering Committee and Investigators. Ticagrelor versus aspirin in acute stroke or transient ischemic attack. N Engl J Med 2016;375:35-43. https://doi.org/10.1056/NEJMoa1603060

13. Lawrence M, Pringle J, Kerr S, Booth J, Govan L, Roberts NJ. Multimodal secondary prevention behavioral interventions for TIA and stroke: a systematic review and meta-analysis. PLoS One 2015;10:e0120902. https://doi.org/10.1371/ journal.pone.0120902

14. Kim JT, Park MS, Choi KH, Cho KH, Kim BJ, Han MK, et al. Different antiplatelet strategies in patients with new ischemic stroke while taking aspirin. Stroke 2016;47:128-34. https://doi.org/10.1161/STROKEAHA.115.011595

15. Lee M, Wu YL, Saver JL, Lee HC, Lee JD, Chang KC, et al. Is clopidogrel better than aspirin following breakthrough strokes while on aspirin? A retrospective cohort study. BMJ Open 2014;4:e006672. https://doi.org/10.1136/ bmjopen-2014-006672

16. Holmes DR Jr, Dehmer GJ, Kaul S, Leifer D, O'Gara PT, Stein CM. ACCF/AHA clopidogrel clinical alert: approaches to the FDA "boxed warning": a report of the American College of Cardiology Foundation Task Force on clinical expert consensus documents and the American Heart Association endorsed by the Society for Cardiovascular Angiography and Interventions and the Society of Thoracic Surgeons. J Am Coll Cardiol 2010;56:321-41. https://doi.org/10.1016/ j.jacc.2010.05.013

17. Topçuoglu MA, Arsava EM, Ay H. Antiplatelet resistance in stroke. Expert Rev Neurother 2011;11:251-63. https://doi.org/10.1586/ern.10.203

18. Giles MF, Rothwell PM. Systematic review and pooled analysis of published and unpublished validations of the $A B C D$ and $A B C D 2$ transient ischemic attack risk scores. Stroke 2010;41:667-73. https://doi.org/10.1161/ STROKEAHA.109.571174

19. Muir KW, Weir CJ, Murray GD, Povey C, Lees KR. Comparison of neurological scales and scoring systems for acute stroke prognosis. Stroke 1996;27:1817-20. https://doi.org/10.1161/01.STR.27.10.1817

20. Wang Y, Pan Y, Zhao X, Li H, Wang D, Johnston SC, et al.; CHANCE Investigators. Clopidogrel with aspirin in acute minor stroke or transient ischemic attack (CHANCE) trial one-year outcomes. Circulation 2015;132:40-6. https://doi.org/10.1161/CIRCULATIONAHA.114.014791

21. Johnston SC, Easton JD, Farrant M, Barsan W, Conwit RA, Elm JJ, et al.; Clinical Research Collaboration, Neurological Emergencies Treatment Trials Network, and the POINT Investigators. Clopidogrel and aspirin in acute ischemic stroke and high-risk TIA. N Engl J Med 2018;379:215-25 https://doi.org/10.1056/NEJMoa1800410

22. Hao Q, Tampi M, O’Donnell M, Foroutan F, Siemieniuk RA Guyatt $\mathrm{G}$. Clopidogrel plus aspirin versus aspirin alone for acute minor ischaemic stroke or high risk transient ischaemic attack: systematic review and meta-analysis. BMJ 2018;363:k5108. https://doi.org/10.1136/bmj.k5108

23. Johnston SC, Amarenco P, Denison H, Evans SR, Himmelmann A, James S, et al.; THALES Investigators. Ticagrelor and aspirin or aspirin alone in acute ischemic stroke or TIA. N Engl J Med 2020;383:207-17. https://doi.org/ 10.1056/NEJMoa1916870

24. Barkat M, Hajibandeh S, Hajibandeh S, Torella F, Antoniou GA. Systematic review and meta-analysis of dual versus single antiplatelet therapy in carotid interventions. Eur J Vasc Endovasc Surg 2017;53:53-67. https://doi.org/ 10.1016/j.ejvs.2016.10.011

25. Saxena R, Koudstaal PJ. Anticoagulants versus antiplatelet therapy for preventing stroke in patients with nonrheumatic atrial fibrillation and a history of stroke or transient ischemic attack. Stroke 2005;36:914-5. https://doi.org/10.1161/ 01.STR.0000161710.96513.e2
26. De Schryver EL, Algra A, Kappelle LJ, van Gijn J, Koudstaal PJ. Vitamin $\mathrm{K}$ antagonists versus antiplatelet therapy after transient ischaemic attack or minor ischaemic stroke of presumed arterial origin. Cochrane Database Syst Rev 2012:CD001342. https://doi.org/10.1002/14651858.CD001342.pub3

27. Ruff CT, Giugliano RP, Braunwald E, Hoffman EB Deenadayalu N, Ezekowitz MD, et al. Comparison of the efficacy and safety of new oral anticoagulants with warfarin in patients with atrial fibrillation: a meta-analysis of randomised trials. Lancet 2014;383:955-62. https://doi.org/10.1016/S0140-6736(13)62343-0

28. Chin PK, Doogue MP. Long-term prescribing of new oral anticoagulants. Aust Prescr 2016;39:200-4. https://doi.org/ 10.18773/austprescr.2016.068

29. Diener HC, Bernstein R, Hart R. Secondary stroke prevention in cryptogenic stroke and embolic stroke of undetermined source (ESUS). Curr Neurol Neurosci Rep 2017;17:64. https://doi.org/10.1007/s11910-017-0775-5

30. Hart RG, Catanese L, Perera KS, Ntaios G, Connolly SJ. Embolic stroke of undetermined source: a systematic review and clinical update. Stroke 2017;48:867-72. https://doi.org/ 10.1161/STROKEAHA.116.016414

31. Hart RG, Sharma M, Mundl H, Kasner SE, Bangdiwala SI, Berkowitz SD, et al.; NAVIGATE ESUS Investigators. Rivaroxaban for stroke prevention after embolic stroke of undetermined source. N Engl J Med 2018;378:2191-201. https://doi.org/10.1056/NEJMoa1802686

32. Diener HC, Sacco RL, Easton JD, Granger CB, Bernstein RA, Uchiyama S, et al.; RE-SPECT ESUS Steering Committee and Investigators. Dabigatran for prevention of stroke after embolic stroke of undetermined source. N Engl J Med 2019;380:1906-17. https://doi.org/10.1056/NEJMoa1813959

33. Sandercock PA, Gibson LM, Liu M. Anticoagulants for preventing recurrence following presumed noncardioembolic ischaemic stroke or transient ischaemic attack. Cochrane Database Syst Rev 2009:CD000248. https://doi.org/10.1002/14651858.CD000248.pub2

34. SPS3 Study Group. Blood-pressure targets in patients with recent lacunar stroke: the SPS3 randomised trial. Lancet 2013;382:507-15. https://doi.org/10.1016/S0140-6736(13)60852-1

35. Ettehad D, Emdin CA, Kiran A, Anderson SG, Callender T, Emberson J, et al. Blood pressure lowering for prevention of cardiovascular disease and death: a systematic review and meta-analysis. Lancet 2016;387:957-67. https://doi.org/ 10.1016/S0140-6736(15)01225-8

36. Whelton PK, Carey RM, Aronow WS, Casey DE, Collins KJ, Himmelfarb CD, et al. 2017 ACC/AHA/AAPA/ABC/ACPM/ AGS/APhA/ASH/ASPC/NMA/PCNA guideline for the prevention, detection, evaluation, and management of high blood pressure in adults: a report of the American College of Cardiology/American Heart Association Task Force on Clinical Practice Guidelines. Hypertension 2018;71:e13-e115. https://doi.org/10.1161/HYP.0000000000000065

37. Mukete BN, Cassidy M, Ferdinand KC, Le Jemtel TH. Longterm anti-hypertensive therapy and stroke prevention: a meta-analysis. Am J Cardiovasc Drugs 2015;15:243-57. https://doi.org/10.1007/s40256-015-0129-0

38. Boan AD, Egan BM, Bachman DL, Adams RJ, Feng WW, Jauch EC, et al. Antihypertensive medication persistence 1-year post-stroke hospitalization. J Clin Hypertens (Greenwich) 2014;16:869-74. https://doi.org/10.1111/jch.12424

39. Hornnes N, Larsen K, Boysen G. Blood pressure 1 year after stroke: the need to optimize secondary prevention. J Stroke Cerebrovasc Dis 2011;20:16-23. https://doi.org/ 10.1016/j.jstrokecerebrovasdis.2009.10.002

40. Toschke AM, Gulliford MC, Wolfe CD, Rudd AG, Heuschmann PU. Antihypertensive treatment after first stroke in primary care: results from the General Practitioner Research Database. J Hypertens 2011;29:154-60. https://doi.org/ 10.1097/HJH.0b013e32833f3897

41. Manktelow BN, Potter JF. Interventions in the management of serum lipids for preventing stroke recurrence. Cochrane Database Syst Rev 2009:CD002091. https://doi.org/10.1002/ 14651858.cd002091.pub2

42. Amarenco P, Bogousslavsky J, Callahan A 3rd, Goldstein LB, Hennerici M, Rudolph AE, et al.; Stroke Prevention by Aggressive Reduction in Cholesterol Levels (SPARCL) Investigators. High-dose atorvastatin after stroke or transient ischemic attack. N Engl J Med 2006;355:549-59. https://doi.org/10.1056/NEJMoa061894 
<ustralian Prescriber

43. Heart Protection Study Collaborative Group. MRC/BHF Heart Protection Study of cholesterol lowering with simvastatin in 20,536 high-risk individuals: a randomised placebo-controlled trial. Lancet 2002;360:7-22. https://doi.org/10.1016/S0140-6736(02)09327-3

44. Ziff OJ, Banerjee G, Ambler G, Werring DJ. Statins and the risk of intracerebral haemorrhage in patients with stroke: systematic review and meta-analysis. J Neurol Neurosurg Psychiatry 2019;90:75-83. https://doi.org/10.1136/jnnp-2018-318483

45. Amarenco P, Kim JS, Labreuche J, Charles H, Abtan J, Béjot $Y$, et al.; Treat Stroke to Target Investigators. A comparison of two LDL cholesterol targets after ischemic stroke. N Engl J Med 2020;382:9-19. https://doi.org/10.1056/ NEJMoa1910355

46. Grundy SM, Stone NJ, Bailey AL, Beam C, Birtcher KK, Blumenthal RS, et al. 2018 AHA/ACC/AACVPR/AAPA/ ABC/ACPM/ADA/AGS/APhA/ASPC/NLA/PCNA Guideline on the management of blood cholesterol: a report of the American College of Cardiology/American Heart Association Task Force on Clinical Practice Guidelines. Circulation 2019;139:1082-43. https://doi.org/10.1161/ CIR.0000000000000625
47. Cannon CP, Blazing MA, Giugliano RP, McCagg A, White JA, Theroux P, et al.; IMPROVE-IT Investigators. Ezetimibe added to statin therapy after acute coronary syndromes. N Engl J Med 2015;372:2387-97. https://doi.org/10.1056/ NEJMoa1410489

48. Zhan S, Tang M, Liu F, Xia P, Shu M, Wu X. Ezetimibe for the prevention of cardiovascular disease and all-cause mortality events. Cochrane Database Syst Rev 2018:CD012502. https://doi.org/10.1002/14651858.CD012502.pub2

49. Corvol JC, Bouzamondo A, Sirol M, Hulot JS, Sanchez P, Lechat P. Differential effects of lipid-lowering therapies on stroke prevention: a meta-analysis of randomized trials. Arch Intern Med 2003;163:669-76. https://doi.org/10.1001/ archinte.163.6.669

50. Wang D, Liu B, Tao W, Hao Z, Liu M. Fibrates for secondary prevention of cardiovascular disease and stroke. Cochrane Database Syst Rev 2015;(10):CD009580. https://doi.org/10.1002/14651858.CD009580.pub2 